\title{
Cast versus splint in children with minimally angulated fractures of the distal radius: a randomized controlled trial
}

\author{
Kathy Boutis MD, Andrew Willan PhD, Paul Babyn MD, Ron Goeree MA, Andrew Howard MD \\ Previously published at www.cmaj.ca
}

\section{ABSTRACT}

Background: Minimally angulated fractures of the distal radius are common in children and have excellent outcomes. We conducted a randomized controlled trial to determine whether the use of a prefabricated splint is as effective as a cast in the recovery of physical function.

Methods: We included 96 children 5 to 12 years of age who were treated for a minimally angulated $\left(\leq 15^{\circ}\right)$ greenstick or transverse fracture of the wrist between April 2007 and September 2009 at a tertiary care pediatric hospital. Participants were randomly assigned to receive either a prefabricated wrist splint or a short arm cast for four weeks. The primary outcome was physical function at six weeks, measured using the performance version of the Activities Scale for Kids. Additional outcomes included the degree of angulation, range of motion, grip strength and complications.

Results: Of the 96 children, 46 received a splint and 50 a cast. The mean Activities Scale for Kids score at six weeks was 92.8 in the splint group and 91.4 in the cast group (difference $1.44,95 \%$ confidence interval $[\mathrm{Cl}]-1.75$ to 4.62). Thus, the null hypothesis that the splint is less effective by at least seven points was rejected. The betweengroup difference in angulation at four weeks was not statistically significant $\left(9.85^{\circ}\right.$ in the splint group and $8.20^{\circ}$ in the cast group; mean difference $1.65^{\circ}, 95 \% \mathrm{Cl}-1.82^{\circ}$ to $5.11^{\circ}$ ), nor was the between-group differences in range of motion, grip strength and complications.

Interpretation: In children with minimally angulated fractures of the distal radius, use of a splint was as effective as a cast with respect to the recovery of physical function. In addition, the devices were comparable in terms of the maintenance of fracture stability and the occurrence of complications. (ClinicalTrials.gov trial register no. NCT00610220.)

$\mathrm{F}$ ractures of the distal radius are the most common fracture in childhood ${ }^{1}$ and a frequent reason for visits to the emergency department. ${ }^{2}$ Although such frac2 tures are often angulated at the time of injury, physicians often accept those with minimal angulation $\left(\leq 15^{\circ}\right)$ because of the unique capacity of skeletally immature bones in children to heal through remodelling. ${ }^{3-5}$ These minimally angulated fractures generally do not require reduction, have an excellent long-term prognosis and rarely result in complications such as malunion or deformity. $3,5,6$
The mainstay of treatment for these fractures has been the use of a short arm cast for four to six weeks and several follow-up visits to an orthopedic surgeon. ${ }^{3,5}$ However, a cast complicates hygiene for a child, and there may be risks that result from a poor fit. ${ }^{7}$ The noise from a cast saw and fear of its use, as well as discomfort of the cast are among the most common negative aspects from a child's perspective..$^{8-10}$ Finally, there is the need for specialized resources for application and removal of the cast. Preliminary evidence from studies involving adults 11,12 and studies of stable buckle fractures of the distal radius ${ }^{13-16}$ suggest that splinting offers a safe alternative. However, this approach needs to be compared with the traditional use of casting in children who have minimally angulated and potentially unstable fractures of the distal radius before it can be recommended for clinical practice.

We conducted a noninferiority randomized controlled trial to determine whether a prefabricated wrist splint was as effective as routine casting in the recovery of physical function at six weeks in children who had a minimally angulated greenstick or transverse fracture of the distal radius. We also compared fracture angulation, range of motion, grip strength, complications and level of satisfaction.

\section{Methods}

\section{Study patients}

Enrolment occurred from April 2007 to September 2009 at The Hospital for Sick Children, a tertiary care pediatric centre that serves the Greater Toronto Area (population of about 5.5 million) in the province of Ontario. Children were eligible if they were between 5 and 12 years of age, had open growth plates and presented to the emergency department with a minimally angulated or a minimally displaced acute greenstick or transverse fracture of the metaphyseal portion of the distal radius (see radiographs in Appendix 1, available at www.cmaj.ca/cgi/content/full/cmaj.100119/DC1). Our

From the Departments of Pediatrics (Boutis), Radiology (Babyn) and Surgery (Howard), The Hospital for Sick Children, University of Toronto, Toronto, Ont.; the SickKids Research Institute (Willan, Howard), Toronto, Ont.; the Dalla Lana School of Public Health (Willan), University of Toronto, Toronto, Ont.; the Department of Clinical Epidemiology and Biostatistics (Goeree), McMaster University, Hamilton, Ont.; and the PATH Research Institute (Goeree), St. Joseph's Healthcare, Hamilton, Ont.

CMAJ 2010. DOI:10.1503/cmaj.100119 
definition of minimal angulation was a fracture with angulation of $15^{\circ}$ or less in the sagittal plane of the radiograph. ${ }^{3-5}$ Minimal displacement was defined as translational displacement of $5 \mathrm{~mm}$ or less on the frontal plane.,

We excluded patients whose injuries were older than five days and those who had a buckle (torus), growth-plate or open fracture. We also excluded children at risk of pathologic fractures, those with congenital anomalies of the wrists, coagulopathies, multisystem trauma or multiple injuries to the same limb, and those with developmental delay. A record of patients missed was kept to assess for enrolment bias.

The study design was approved by The Hospital for Sick Children's Research Ethics Board.

\section{Recruitment and baseline assessment}

The research assistants were certified cast technicians trained to identify eligible children. The triage nurses in the emergency department alerted the research assistants about all children with wrist injuries daily between 8 am and $11 \mathrm{pm}$. The children and their respective radiographs were assessed by a pediatric emergency physician and the radiologist on call. When a child met the eligibility criteria, informed consent and relevant assent was obtained.

Demographic and clinical data were collected for each participant. To determine their physical function during the week before the injury, the children were asked to complete the performance version of the Activities Scale for Kids (see the section "Outcome measures" for details), with assistance from their parents as needed. ${ }^{17-20}$

\section{Randomization}

Recruited patients were randomly assigned to receive either a short arm cast made out of fibreglass or a prefabricated wrist splint (W-312 Pediatric Thermoplastic Wrist Support, Benik Corporation, Silverdale, USA). Concealed allocation of treatment was provided by an online program (www.randomize.net) using block randomization with random block sizes of three and six.

\section{Study interventions}

A research cast technician placed either the fibreglass cast or the splint. The participants wore the immobilization device for four weeks and were advised to avoid activities that could re-injure the wrist for a further two weeks. Children in the splint group were instructed to always wear the splint except for removal as needed for hygienic reasons. Apart from specific instructions regarding care of the cast or the splint, both study groups received identical instructions.

All participants attended the fracture clinic at the study hospital at one and four weeks after the injury. At each of these visits, a radiograph of the wrist was obtained and examined by a staff orthopedic surgeon who was unaware of the treatment allocation. The families were asked to complete a clinical diary to record weekly pain scores and compliance with the splint if applicable. All immobilization devices were removed at four weeks at the fracture clinic.

All radiographs were first read as per routine clinical care. To ensure consistency and accuracy of initial diagnoses, a pediatric musculoskeletal radiologist 
(P.B.), who was unaware of the treatment allocation, reviewed the radiographs obtained at baseline and at one and four weeks after injury. Any differences of opinion between this review and the initial diagnoses were resolved by consensus between the collaborating orthopedic surgeon (A.H.) and radiologist (P.B.).

Six weeks after the injury, patients were visited at home by a research physiotherapist unaware of the treatment allocation. To preserve blinding, families were instructed not to reveal which immobilization device had been used, and patients were provided with an opaque stocking that was placed over the affected arm before the physiotherapist's assessment to hide any indications of which device had been used. At this visit, children completed the performance version of the Activities Scale for Kids with the physiotherapist without assistance from family members, and the therapist measured grip strength and range of motion of the wrist. Parents completed the clinical diary and were asked to report any complications, level of satisfaction and preferences related to the immobilization device. Three months after the injury, parents were telephoned by a research assistant unaware of treatment allocation to assess recovery and any subsequent complications.

\section{Outcome measures}

The primary outcome measure was physical function at six weeks, measured with the performance version of the Activities Scale for Kids. ${ }^{17-20}$ Physical function was chosen as the primary outcome because it provides clinically meaningful information to families and physicians. Although other outcomes such as angulation and range of motion are also important, their significance rests mostly on the impact they have on physical function and thus were considered as secondary outcomes.

The performance version of the Activities Scale for Kids is used to assess a child's current physical function based on activities performed during the week before completing the questionnaire. ${ }^{17}$ The questionnaire has 30 items related to clinicians' and children's perspectives on pediatric daily activities and 8 additional questions related more specifically to activity of the wrist. This modified scale has been used in another trial assessing wrist function after fracture. ${ }^{15}$ The scale has been found to be highly reliable, ${ }^{19,20}$ have excellent construct validity and be responsive to change. ${ }^{17-20}$ It has been validated in populations of children 5 to 15 years old with fractures and other musculoskeletal problems. ${ }^{17}$

Secondary outcome measures included fracture angulation, measured at weeks 1 and 4; wrist pain, measured at weeks 1, 4 and 6 with the use of the Faces Pain Scale - Revised; ${ }^{21,22}$ weekly use of the splint, if applicable, measured on a Likert scale; range of motion, measured at week 6 with a goniometer, ${ }^{23,24}$ grip strength, measured at week 6 with a dynamometer; and patient preference for their device, measured at week 6 .

\section{Statistical analysis}

All analyses were by intention to treat. The sample size was based on the primary outcome and determined using methods appropriate for noninferiority trials. ${ }^{25-27}$ The minimum required sample of 76 patients was based on testing the null hypothesis that the splint is less effective than a cast by at least seven points on the Activities Scale for Kidsperformance score at six weeks, at the $2.5 \%$ level, with an $80 \%$ probability of rejecting the null hypothesis if the splint and cast were equally effective. We chose a seven-point difference in effectiveness because it is approximately the difference in average scores between patients with normal ability and those considered to be mildly disabled on the performance version of the Activities Scale for Kids. ${ }^{28}$ In addition, the sample size was inflated by $20 \%$ to account for dropouts, crossovers and patients lost to follow-up. The null hypothesis, based on the Activities Scale for Kids scores at week six, was tested by a $t$ test for a non-zero difference. For the other clinical outcomes, traditional zero null hypotheses were tested. Proportions were compared with the Fisher exact test. Pain scores and angulation were compared with the Student $t$ test. Analysis of covariance was used to compare grip strength and range of motion, where the covariate was the corresponding measure on the unaffected wrist. We used the Cochrane test for trend to compare treatment arms with respect to the ordered categoric outcome of patient satisfaction.

\section{Results}

During the study period, 622 children with a wrist injury were seen in the emergency department. Of the 100 children randomly assigned to the treatment groups (50 in each group), 4 assigned to the splint group were removed from the study because of diagnostic errors (Figure 1). Baseline characteristics are summarized in Table 1.

Follow-up of the primary outcome at six weeks was completed in $92(96 \%)$ of the 96 children. Blinding was assessed at this visit, and for 90 of the 92 patients the physiotherapist

Table 1: Baseline characteristics of 96 children with a minimally angulated fracture of the distal radius randomly assigned to receive either a prefabricated splint or a cast

\begin{tabular}{|c|c|c|}
\hline Characteristic & $\begin{array}{l}\text { Splint group } \\
\quad n=46\end{array}$ & $\begin{array}{l}\text { Cast group } \\
\quad n=50\end{array}$ \\
\hline Age, yr, mean (SD) & $9.0(2.6)$ & $9.6 \quad(2.1)$ \\
\hline Sex, male, no. (\%) & $32(70)$ & $31(62)$ \\
\hline Hours since injury, mean (SD) & $19.2(30.5)$ & $18.8(25.0)$ \\
\hline $\begin{array}{l}\text { Physical function score, }{ }^{*} \\
\text { mean (SD) }\end{array}$ & $91.2(8.7)$ & $92.3 \quad(6.3)$ \\
\hline Pain (score 0-5), mean (SD) & $2.7 \quad(1.3)$ & $2.3 \quad(1.2)$ \\
\hline $\begin{array}{l}\text { Angulation of radial fracture, } \\
\text { degrees, mean (SD) }\end{array}$ & $6.6(6.1)$ & $5.9(6.9)$ \\
\hline \multicolumn{3}{|l|}{ Type of fracture, no. (\%) } \\
\hline \multicolumn{3}{|l|}{ Radius (distal metaphyseal) } \\
\hline Greenstick & $24(52)$ & $31(62)$ \\
\hline Transverse & $22(48)$ & $19(38)$ \\
\hline \multicolumn{3}{|l|}{$\begin{array}{l}\text { Associated ulna (distal } \\
\text { metaphyseal) }\end{array}$} \\
\hline Buckle & $9(20)$ & $13(26)$ \\
\hline Ulnar styloid & $2(4)$ & $3(6)$ \\
\hline
\end{tabular}

Note: $\mathrm{SD}=$ standard deviation.

*Measured using the performance version of the Activities Scale for Kids. ${ }^{17}$ 
could not ascertain which immobilization device had been used. All of the parents completed the clinical diary at one and four weeks; 92 (96\%) completed the diary at six weeks and were successfully contacted at three months. The parents of the four patients lost to follow-up during the six-week study period were contacted by phone at the final three-month follow-up; they, like the parents of the other children contacted at this time, reported no pain or additional complications and a full resumption of their child's usual activities.

\section{Physical function}

The between-group difference in mean scores for the performance version of the Activities Scale for Kids was 1.44 (95\% confidence interval $[\mathrm{CI}]-1.75$ to 4.62 ) (Table 2). Thus, the null (inferiority) hypothesis that the splint is less effective than the cast by at least seven points was rejected with a $p$ value of less than 0.0001 . The between-group differences in range of motion, grip strength and pain did not differ significantly at any of the respective time points (Table 2).
Table 2: Between-group differences in outcomes among 96 children with a minimally angulated fracture of the distal radius given either a splint or a cast

\begin{tabular}{|c|c|c|c|c|c|}
\hline \multirow[b]{2}{*}{ Outcome } & \multicolumn{2}{|c|}{ Splint } & \multicolumn{2}{|c|}{ Cast } & \multirow{2}{*}{$\begin{array}{l}\text { Mean difference } \\
(95 \% \mathrm{Cl})\end{array}$} \\
\hline & $n$ & Mean & $n$ & Mean & \\
\hline \multicolumn{6}{|c|}{$\begin{array}{l}\text { Physical function } \\
\text { score* }\end{array}$} \\
\hline Week 6 & 43 & 92.8 & 49 & 91.4 & $1.44(-1.75$ to 4.62$)$ \\
\hline \multicolumn{6}{|l|}{$\begin{array}{l}\text { Angulation, } \\
\text { degrees }\end{array}$} \\
\hline Week 1 & 46 & 8.65 & 48 & 7.92 & $-2.43(-2.43$ to 3.90$)$ \\
\hline Week 4 & 46 & 9.85 & 50 & 8.20 & $-1.65(-1.82$ to 5.11$)$ \\
\hline \multicolumn{6}{|c|}{$\begin{array}{l}\text { Range of motion } \\
\text { at week } 6 \text {, degree }\end{array}$} \\
\hline Flexion & 42 & 70.4 & 47 & 74.7 & $-4.27(-9.40$ to 0.86$)$ \\
\hline Extension & 42 & 67.3 & 47 & 65.6 & $1.65(-2.97$ to 6.27$)$ \\
\hline Pronation & 40 & 84.3 & 47 & 74.3 & 9.93 (2.73 to 17.13$)$ \\
\hline Supination & 42 & 56.3 & 47 & 52.9 & $3.36(-8.21$ to 14.93$)$ \\
\hline Inversion & 42 & 37.3 & 47 & 35.6 & $1.74(-2.27$ to 5.75$)$ \\
\hline Eversion & 42 & 28.4 & 47 & 28.6 & -0.28 ( -4.42 to 3.87$)$ \\
\hline \multicolumn{6}{|c|}{ Grip strength (lbs) } \\
\hline Week 6 & 42 & 26.6 & 47 & 28.8 & $-2.16(-7.34$ to 3.02$)$ \\
\hline \multicolumn{6}{|c|}{ Pain (score 0-5) } \\
\hline Week 1 & 46 & 0.61 & 50 & 0.88 & $-0.271(-0.601$ to 0.059$)$ \\
\hline Week 4 & 44 & 0.16 & 50 & 0.26 & $-0.101(-0.280$ to 0.078$)$ \\
\hline Week 6 & 42 & 0.12 & 47 & 0.06 & $0.055(-0.066$ to 0.177$)$ \\
\hline
\end{tabular}

*Measured using performance version of the Activities Scale for Kids. ${ }^{17}$

Table 3: Minor complications from the immobilization devices recorded by the parents of 89 children with a minimally angulated fracture of the distal radius*

\begin{tabular}{|c|c|c|c|}
\hline \multirow[b]{2}{*}{ Complication } & \multicolumn{2}{|c|}{ Group; no. (\%) of children } & \multirow[b]{2}{*}{$\begin{array}{c}\text { Risk difference, } \\
\%(95 \% \mathrm{Cl})\end{array}$} \\
\hline & $\begin{array}{l}\text { Splint } \\
n=42\end{array}$ & $\begin{array}{l}\text { Cast } \\
n=47\end{array}$ & \\
\hline Irritation & $25(60)$ & $19(40)$ & $19.10 \quad(-1.74$ to 39.94$)$ \\
\hline Pain & $6(14)$ & $7(15)$ & $-0.61(-15.59$ to 14.38$)$ \\
\hline Sores & $10(24)$ & $4 \quad(9)$ & $15.30 \quad(-0.16$ to 30.76$)$ \\
\hline Itching & $37(88)$ & $34(72)$ & 15.75 ( -0.68 to 32.19$)$ \\
\hline Discomfort & $8(19)$ & $12(26)$ & $-6.48(-24.05$ to 11.08$)$ \\
\hline
\end{tabular}

Note: $\mathrm{Cl}=$ confidence interval.

* Of the 92 parents who submitted diaries, 3 did not complete the section on complications.

\section{Angulation}

The mean fracture angulation did not differ significantly between the two groups at one and four weeks (Table 2). Six children (three in each group) had to wear the immobilization device for six weeks because their fracture angulation had progressed to $25^{\circ}$ at the four-week visit. None of the patients had a clinical deformity at the four-week visit, and none required a surgical intervention at any point in the three-month follow-up period.

\section{Complications}

Three of the 50 children in the cast group had to return to the fracture clinic within the first week to have the cast replaced because of cast breakage. Of these, one received a splint at one week because of cast discomfort. In the splint group, one child had a rash on the forearm from the splint and received a cast at one week.

None of the participants experienced serious adverse reactions. Several children in both groups described irritation, itching and discomfort from the device (Table 3); the differences were not statistically significant between the treatment groups.

Although patients in the splint group were instructed to remove the splint only as needed for hygiene, in the first week $94 \%$ of the patients used the splint "always," 4\% "often" and 2\% "sometimes." By week four, 57\% of the patients wore the splint "always," $33 \%$ "often" and 9.5\% "sometimes." According to reports from the parents and children, removal of the splint occurred almost exclusively for hygiene or because of irritation.

\section{Patient and parent satisfaction and preference}

At six weeks, all of the parents in both groups reported that they were satisfied with the appearance of the wrist; 18 $(43 \%)$ of 42 in the splint group and 20 
(43\%) of 47 in the cast group were "completely" satisfied $(p=0.52)$. Of the children assigned to the splint group, $12 \%$ reported that they would have preferred a cast, as compared with $68 \%$ of the children assigned to cast group who reported a preference for a splint $(p<0.001)$. Likewise, $5 \%$ of the parents of children assigned to the splint group reported that they would have preferred a cast, as compared with $60 \%$ of the parents of children in the cast group who would have preferred the splint $(p<0.001)$.

\section{Interpretation}

Our study showed that use of a prefabricated splint was as effective as a short arm cast in children with minimally angulated greenstick or transverse fractures of the distal radius with respect to recovery of physical function. In addition, the groups did not differ significantly with regard to the maintenance of fracture stability and the occurrence of complications, and the splint was superior to the cast in terms of parental and patient satisfaction and preferences. Inherent benefits of a prefabricated splint include easier hygiene, less discomfort and anxiety associated with the use of a cast saw, ${ }^{8-10}$ less discomfort with use of the splint, and easy application and removal. Thus, evidence from this research combined with the advantages of the splint support the use of this device in the treatment of these fractures.

The use of splinting instead of casting has been previously established for buckle fractures of the distal radius in children $^{13-16}$ and Colles fractures in adults. ${ }^{11,12}$ Our results contribute to the growing body of evidence that splinting is a suitable alternative to casting for specific fractures of the distal radius. Although we included children with fractures that were less stable than buckle fractures, both groups in our study had normal physical function, normal range of motion and no clinical deformity after treatment.

The lack of serious complications in our study is consistent with what has been reported for minimally angulated fractures of the distal radius in children. ${ }^{3,4,6}$ The safe use of a splint for fractures with an excellent long-term prognosis has implications for management of these injuries. Given that the splint can be applied or taken off easily by any health care provider and does not require the specialized services of an orthopedic technologist or surgeon allows for definitive treatment of these injuries during the first patient encounter in an emergency department or urgent care clinic rather than during a separate visit at a fracture clinic. The splint obviates the technical challenges and associated potential complications ${ }^{7,29}$ that may be an issue with those less skilled in the placement of casts. Further, the rarity of complications that require surgical intervention ${ }^{3,4,6}$ for either immobilization device minimizes the need for what is often weekly follow-up with an orthopedic surgeon. ${ }^{1,3}$

\section{Limitations}

Our study has limitations. The sample size was determined based on power considerations for the primary outcome of recovery of physical function at six weeks. Therefore, the trial may have lacked power to detect important differences with respect to the other outcomes. A larger sample may have also identified the occurrence of rarer adverse events. Because families were aware of treatment allocation, this may have introduced bias in the measurement of our outcomes. It is uncertain whether the high rate of compliance with the splint during the four weeks of treatment reflected the increased vigilance that patients received during the study. Finally, even though this study was conducted at a centre where physicians have expertise in diagnosing fracture types, four patients were removed from the study because of diagnostic errors. Physician error in assessing whether a splint is suitable for fracture management may occur with greater frequency in less specialized centres, limiting the generalizability of our results.

\section{Conclusion}

In children with minimally angulated greenstick or transverse fractures of the distal radius, use of a prefabricated splint was as effective as a short arm cast with respect to recovery of physical function. In addition, the devices did not differ significantly with regard to the maintenance of fracture stability and the occurrence of complications, and the splint was superior to the cast in terms of parental and patient satisfaction and preferences.

\section{This article has been peer reviewed.}

Competing interests: None declared.

Contributors: Kathy Boutis was the principal author; she designed the study, oversaw all research operations in patient enrolment and data collection and entry, and was involved in the analysis and interpretation of results. Andrew Willan contributed to the study design and was involved in the analysis of the results. Paul Babyn and Ron Goeree contributed to the study design. Andrew Howard contributed to the study design and was involved in patient enrolment and the analysis and interpretation of results. All of the authors revised the article critically for important intellectual content and gave final approval of the version to be published.

Acknowledgements: The authors thank Benik Corporation for providing the prefabricated wrist splints used in the study. They also thank Johanna Crudden for her tireless efforts as research coordinator of the study and Dr. Martin Pecaric of Contrail Consulting Services for database design and data entry.

Andrew Willan is funded by the Discovery Grant Program of the Natural Sciences and Engineering Research Council of Canada (grant no. 44868-08).

Funding: The study was funded by the SickKids Foundation (grant no. XG 07-001). Neither the foundation nor Benik Corporation had any input into the study design, the collection, analysis or interpretation of the data, or the preparation of the article.

\section{REFERENCES}

1. Bohm ER, Bubbar V, Yong Hing K, et al. Above and below-the-elbow plaster casts for distal forearm fractures in children. A randomized controlled trial. J Bone Joint Surg Am 2006;88:1-8.

2. Bachman D, Santora S. Orthopedic trauma. In: Fleisher G, Ludwig S, Henretig FM, et al., editors. Textbook of pediatric emergency medicine. Philadelphia (PA): Lippincott Williams \& Wilkins; 2000. p. 1455-7.

3. Al Ansari K, Howard A, Seeto B, et al. Minimally angulated pediatric wrist fractures: Is casting without manipulation enough? CJEM 2007;9:9-15.

4. Do TT, Strub WM, Foad SL, et al. Reduction versus remodeling in pediatric distal forearm fractures: a preliminary cost analysis. J Pediatr Orthop B 2003;12:109-15.

5. Waters PM. Distal radius and ulna fractures. In: Beaty JH, Kasser JR, editors. Fractures in children. Philadelphia (PA): Lippincott Williams \& Wilkins; 2001.

6. Wilkins KE. Principles of fracture remodeling in children. Injury 2005;36:A3-11.

7. Boyd AS, Benjamin HJ, Asplund C. Principles of casting and splinting. Am Fam Physician 2009;79:16-22.

8. Carmichael KD, Westmoreland J. Effectiveness of ear protection in reducing anxiety during cast removal in children. Am J Orthop 2005;34:43-6.

9. Katz K, Fogelman R, Attias J, et al. Anxiety reaction in children during removal of their plaster cast with a saw. J Bone Joint Surg Br 2001;83:388-90.

10. Liu RW, Mehta P, Fortuna S, et al. A randomized prospective study of music therapy for reducing anxiety during cast room procedures. J Pediatr Orthop 2007;27:831-3. 
11. Ferris BD, Thomas NP, Dewar ME, et al. Brace treatment of Colles' fracture. Acta Orthop Scand 1989;60:63-5.

12. Sarmiento A, Zagorski JB. WF S. Functional bracing of Colles' fractures: a prospective study of immobilization in supination vs. pronation. Clin Orthop Relat Res 1980;146:175-83.

13. Davidson JS, Brown DJ, Barnes SN, et al. Simple treatment for torus fractures of the distal radius. J Bone Joint Surgery Br 2001;83:1173-5.

14. Oakley E, Ooi KS, Barnett PL. A randomized controlled trial of 2 methods of immobilizing torus fractures of the distal forearm. Pediatr Emerg Care 2008;24: 65-70.

15. Plint AC, Perry JJ, Correll R, et al. A randomized, controlled trial of removable splinting versus casting for wrist buckle fractures in children. Pediatrics 2006;117 691-7.

16. Abraham A, Handoll HHG, Khan T. Interventions for treating wrist fractures in children. Cochrane Database Syst Rev 2008;(2):CD004576.

17. Young NL, Wiliams JI, Joshida KK, et al. Measurement properties of the Activities Scale for Kids. J Clin Epidemiol 2000;53:125-37.

18. Young NL, Williams JI, Yoshida KK, et al. The context of measuring disability: Does it matter whether capability or performance is measured? J Clin Epidemiol 1996;49:1097-101.

19. Young NL, Wright JG. Measuring pediatric physical function. J Pediatr Orthop 1995; 15:244-53.

20. Young NL, Yoshida KK, Williams JI, et al. The role of children in reporting their physical disability. Arch Phys Med Rehabil 1995;76:913-8.

21. Hicks CL, von Baeyer CL, Spafford PA, et al. The Faces Pain Scale-Revised: toward a common metric in pediatric pain measurement. Pain 2001;93:173-83.
22. Bieri D, Reeve RA, Champion GD, et al. The Faces Pain Scale for the selfassessment of the severity of pain experienced by children: development, initial validation, and preliminary investigation for ratio scale properties. Pain 1990;41:139-50.

23. Gajdosik RL, Bohannon RW. Clinical measurement of range of motion. Review of goniometry emphasizing reliability and validity. Phys Ther 1987;67:1867-72.

24. Rheault W, Miller M, Nothnagel P, et al. Intertester reliability and concurrent validity of fluid-based and universal goniometers for active knee flexion. Phys Ther 1988;68:1676-8.

25. Blackwelder WC, Chang MA. Sample size graphs for proving the null hypothesis Control Clin Trials 1984;5:97-105.

26. Dunnett CW, Gent M. Significance testing to establish equivalence between treatments, with special reference to data in the form of $2 \mathrm{X} 2$ tables. Biometrics 1977;33:593-602.

27. Farrington CP, Manning G. Test statistics and sample size formulae for comparative binomial trials with null hypothesis of non-zero risk difference or non-unit relative risk. Stat Med 1990;9:1447-54.

28. Plint AC, Gaboury I, Owen J, et al. Activities Scale for Kids: an analysis of normals. J Pediatr Orthop 2003;23:788-90.

29. Bakody E. Orthopaedic plaster casting: nurse and patient education. Nurs Stand 2009;23:49-56.

Correspondence to: Dr. Kathy Boutis, Department of Pediatrics, The Hospital for Sick Children, 555 University Ave., Toronto ON M5G1X8; boutis@pol.net

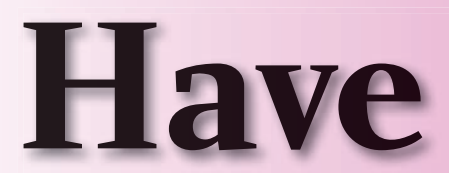

\section{Seasonale is indicated for the Prevention of Pregnancy.}

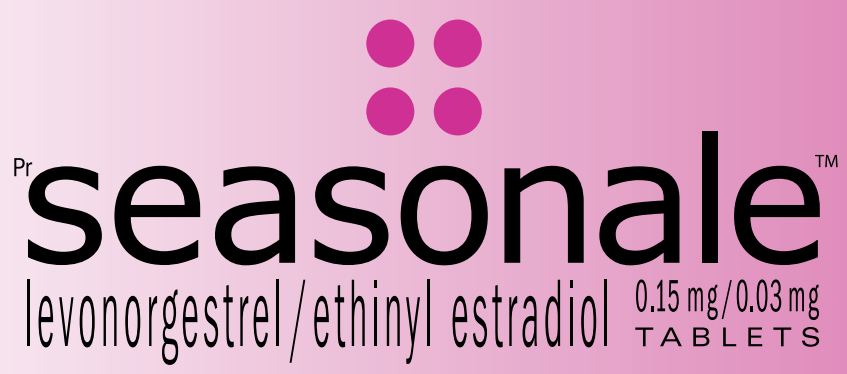

Product Monograph available upon request.

®Seasonale is a registered trademark of Duramed Pharmaceuticals, Inc.

Distributed by: Paladin Labs Inc. Montreal, QC H4P 2T4. Marketed by Warner Chilcott Canada Co.

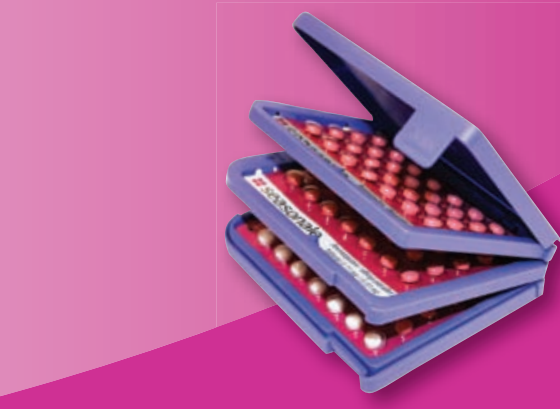

we 